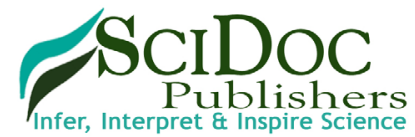

International Journal of Food Science, Nutrition and Dietetics (IJFS)

ISSN:2326-3350

\title{
Characterization of CHIA Seed Flour and Wellbeing Endorsing Possessions
}

\section{Review Article}

Rana $\mathrm{M}^{*}$

School of Nutrition and Dietetics, The University of Faisalabad, Pakistan.

\section{Abstract}

Chia an ancient plant commonly known as Salvia hispanica L. exhibit tremendous dietary and health related medicinal properties. Now a day's seeds of chia gained much attention due to its incredible health benefits and incorporation in different products for improved nutritional and functional attributes. Chia seed flour was analyzed for its chemical composition. It is an excellent source of nutrients containing protein $19.84 \% \pm 1.40$, fats $37.40 \pm 1.41 \%$, fiber $37.82 \pm 1.19 \%$. Moisture and ash content of chia seed flour was $5.86 \pm 0.30 \%$ and $4.00 \pm 0.36 \%$ respectively. Owing to its remarkable gelling and binding properties, water holding and oil holding capacity of chia seed flour was $12.06 \pm 0.32 \%$ and $19.33 \pm 0.59 \%$, can be used as appetite suppressant. The water absorption index and solubility index values of chia seed flour was $2.98 \pm 0.14$ and $9.22 \pm 0.74$. The concoction arrangement and innovative properties of chia give the plant a high healthful potential. Chia is a decent wellspring of polyunsaturated fats: omega-3 and omega- 6 , dissolvable dietary fiber. It likewise contains obvious measure of proteins and phytochemicals. Nutritious estimation of chia is the motivation behind why it is utilized as a part of prophylaxis of a few non-irresistible infections for example obesity, hypertension, cardiovascular maladies, cancer and diabetes. Nutritious and restorative parts of chia are presently being looked into by numerous logical focuses. The point of this article is to exhibit the nutritious and restorative estimations of chia.

Keywords: CHIA Seeds; Salvia Hispanica; Health; Fatty Acids.

\section{Introduction}

With the sky rising increase in global population, food demand increases worldwide but with this there is awareness among people regarding balanced food and exclusive trend in the developing countries with regard to food consumption has shown tremendous increase in preference by the consumers towards the food that is balanced, safe nutritionally adequate and ready to eat [24]. Our daily diet plays a vital role in maintaining good health. Epidemiological researches share the same view, in regard to the relationship of diet in the prevention of various types of diseases especially chronic diseases. Many developed countries have an increased ratio of cardiac issues, type 2 diabetes and hypertension. Occurrence of such health-related ailments can be minimized if proper nutrition filled diet is consumed [8]. According to global burden of disease in 2010, about 8 million deaths have been reported due to cancer, 12.9 million from ischemic heart diseases and strokes and 1.3 million deaths due to diabetes [32]. Currently many natural ingredients have been known for their nutraceutical property and their incorporation in different food products can prove helpful in combating many chronic diseases. Purposely, use of ancestral seeds such as amaranth, quinoa and chia seeds can be used as best alternative in food industry for their nutritional and medicinal properties.

Around $3500 \mathrm{BC}$, chia seeds were first utilized in human dietary interventions. It labeled itself as an important crop in the city of Central Mexico around the time period of $1500 \mathrm{BC}$ and $900 \mathrm{BC}$. The nations known as Mayas and Aztecs got benefit from these seeds by using them in making therapeutic diets. In today's date, chia seeds play an extensive role in the food, cosmetics, animal feed and pharmaceutical industries because of its nutritional importance [39]. The word chia is derived from Nahuatl and Spanish word "Chian" that means "oily". It is also considered to be derived from Latin word "Salvere" meaning the one that heals $[17$, 18, 22]. Various designations like "Chia sage" and "Spanish sage" are also used to represent the same specie [31]. Lamiaceae family from Mexico and Guatemala Salvia hispanica L. is the home to the plant known as chia. Chia seeds can be either black or white and has an arrangement of leaves in opposite manner and can grow 1

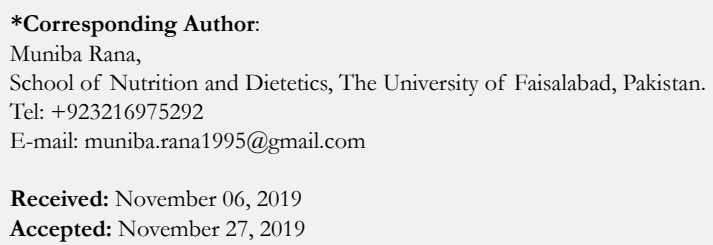

Copyright: Muniba Rana ${ }^{\circ}$ 2019. This is an open-access article distributed under the terms of the Creative Commons Attribution License, which permits unrestricted use, distribution and reproduction in any medium, provided the original author and source are credited. 
meter in length. Chia flowers in size are about $34 \mathrm{~mm}$ and consist of small corollas. Chia seeds are oval shaped with size of approximately $1 \mathrm{~mm}$ to around $2 \mathrm{~mm}$ [38].

Chia seeds can offer wide range of benefits, as they are rich in various essential nutrients which can promote high energy levels, aid in digestion, suppress appetite and provide satiety. Constituents like chlorogenic acid, caffeic acid, quercetin, myricetin and kaempferol accounts for anti-oxidative potential of chia seeds and are believed to execute hepato protective and cardiac effects along with anti-carcinogenic and anti-aging properties. Its generous stores of soluble dietary fiber, gluten free proteins, unsaturated fatty acids, phenolic compounds, vitamins and minerals aid in digestion and regulation of blood sugar levels thus keeping control of diabetes mellitus. Scientific literature validates that chia seeds execute anti-blood clotting, anti-inflammatory, anti-oxidant, laxative, analgesic, immune improving, diabetes controlling, stress relieving and preventing characteristics [54].

Chia was one of the major crops after maize and soybean that is cultivated in South America by pro-columbian societies. It remained as a vital ingredient in human diets for an extensive period. In $20^{\text {th }}$ century, chia was revitalized by researchers and farmers due to its functional, healthy and nutritious ingredients [6]. Chia comprises $9.44 \mathrm{~g}$ of protein and $25.69 \mathrm{~g}$ of lipids [26] and 19.35 $\mathrm{g}$ of dietary fibers [5]. Lipid fraction comprises of $\omega-3$ linolenic acid and $\omega-6$ linoleic acid $[55,56]$. Dietary fibers present in chia seeds contain lignin which has some antioxidants and cholesterol lowering effect [47]. Standardized nutritional composition of chia seeds showed protein $16-26 \%$, fat 31-34\%, carbohydrate $37-45$ $\%$ and dietary fiber $25-35 \%$ [33].

According to USDA, chia grains comprises of approximately $6.2 \%$ moisture, $31 \%$ lipids, $17.32 \%$ protein, $40.22 \%$ carbohydrates and $35 \%$ total dietary fibers, higher contents of phosphorus, potassium, calcium, magnesium and lower amounts of zinc, iron and sodium. Furthermore, chia is good source of Vitamin A, C and niacin [41]. In addition, chia seed is also a pool of vitamins and minerals that are present in efficient amount. Chia seed contains vitamin $B$ in ample amount; thiamin $(0.62 \mathrm{mg} / 100 \mathrm{~g})$, riboflavin $(0.17 \mathrm{mg} / 100 \mathrm{~g})$, niacin $(883 \mathrm{mg} / 100 \mathrm{~g})$ and folic acid $(49 \mathrm{mg} / 100 \mathrm{~g})$. It also encompasses vitamin C $(1.6 \mathrm{mg} / 100 \mathrm{~g})$, vitamin $\mathrm{E}(0.5 \mathrm{mg} / 100 \mathrm{~g})$ and vitamin $\mathrm{A}(49 \mu \mathrm{g} / 100 \mathrm{~g})$. Chia seed is an excellent cradle of minerals too; $\mathrm{Ca}(631 \mathrm{mg} / 100 \mathrm{~g})$, iron $(7.72 \mathrm{mg} / 100 \mathrm{~g})$, potassium (407mg/100g), magnesium (335mg/100g), phosphorous $(860 \mathrm{mg} / 100 \mathrm{~g})$ and sodium $(16 \mathrm{mg} / 100 \mathrm{~g})$ are present (USDA, 2016).

Chia seeds also possess high antioxidant potential. It is a natural nutrient that contains 18 amino acids involving glutamine, arginine, asparagine, leucine, valine, alanine and is free of cholesterol (Kim and Kim, 2010). Regarding physiochemical properties, chia seeds possess unique water-holding- capacity (WHC) $(110.5 \mathrm{~g} / \mathrm{g}$ ) due to increased proportion of soluble fiber and denaturalized protein. It has been explored that chia seeds swell up and turn into gel form after coming into contact with water. Oil-holdingcapacity $(\mathrm{OHC})$ of chia seeds $(11.67 \mathrm{~g} / \mathrm{g})$ is highly linked with the presence of protein and fat contents along with particle size and the absence of hemicelluloses [49]. Chia seed gum (CSG) readily dissolves in water at environs temperature and produces clear liquid. A little bit change in $\mathrm{pH}$ and temperature can alter solubility in aqueous medium [52].

In chia above $65 \%$ of total fatty acids are omega- 3 linoleic acid [10]. Human body cannot produce essential fatty acids and obtained through diet, chia helps in this regard by supplying docosahexaenoic acid (DHA) and eicosapentaenoic acid (EPA) [28], these have been helpful in health promotion [29]. It is effective against many disorders such as platelet aggregation, cancer, cardiovascular disease, dementia, hypertension, depression, hyper lipidemia, inflamation and Alzheimer's disease [35]. Recommended $\omega-6$ to $\omega-3$ proportion is $3: 1$ or fewer and high proportion of these fatty acids is harmful for person's wellbeing and leads towards chronic disorders. Chia improves these ratios by enhancing $\omega-3$ which is essential in managing the arthritis, cancer along with various cardiovascular diseases [50].

Chia seeds have wide range of food applications in various conutries such as Chile, Argentina, New Zealand, Jpan, Mexico, US, Australia and Canada [9]. According to scientific opinion, it was permitted as novel food in 2009 by European Parliament. Chia seeds or mucilage can act as a stabilizer, emulsifier and thickener agent in various bakery or dairy products i.e. biscuit, bread, cake, ice-cream, pasta, chips, and dessert, gravies and soups. It can also be used as egg as well as oil replacer in cakes. Fiber content present in chia seeds plays an immense role in lowering glycemic index furthermore prolonging the satiety time between the meals [49]. Chia seeds also have great manifestation due to their increased proportion of omega-3fatty acids [37]. Recently, increased demand of chia seeds has been mainly attributed due to its glutenfree property [23]. Chia seeds also offer benefits to culinary purposes. Its uses are associated with the entire seed, seed oil, seed flour and seed mucilage and can be eaten as raw or commonly used in salads, cereals, beverages and salad dressing [58, 59]. Chia being the natural source of omega-3 fatty acids plays an important role in reducing the levels of triglycerides or LDL cholesterol and increasing the blood levels of HDL cholesterol by preventing the formation of clots and plaques in the arteries. Chia seed scan be considered ideal for the proper functioning of intestine as well due to the presence of high proportion of dietary fiber. Chia seeds can aid in controlling the blood sugar levels by delaying the digestion time. Furthermore, it can improve the immune system and prevent the depression and epilepsy. Recently it has been discovered that chia seed contains high proportion of phytosterols, an important nutrient that help to prevent cardiovascular diseases and possess anticancer, antioxidants, antibacterial and antifungal effects [12]. Chia seeds also find their application in treatment of respiratory malaise, kidney problems, eye obstruction (by placing seeds directly under the eye lid) and infection [21].

Ayerza reported that the influence of variable locations on seed color and oil contents and it was observed that growing of chia at different locations does not influence the seed color but oil contents were significantly varied from one location to other under different environmental conditions [4]. It has an economic value because it is a functional food, so it is inevitable to explore the further potential and characteristics of chia that can be helpful in improving its value addition and use [3]. At present oil from chia is a healthy supplement for humans as well as for animals. In human consumption, it is used in confectioneries, supplements and cooking oils [44]. 
The project was aimed to attained following objective:

- To assess the physico-chemical attributes of chia seed flour

\section{Review of Literature}

\section{Nutritional Profile}

Lipids: Lipids are essential nutrients which the human living being necessities to total imperativeness, shape fundamental segments of cell movies and control physiological limits. If there are no enzymatic structures prepared for molding two-fold securities at positions $n-3$ and n-6, the living being can't consolidate unsaturated fats. In like manner, it is imperative to outfit the life frame with a supply of lipids in food. Chia seeds contain $25-40 \%$ of fat, most by far of which is as polyunsaturated unsaturated fats [38]. Because of the procedures of desaturation and extension these acids are changed over into long chain polyenoic acids for example EPA (eicosapentaenoic acid) and DHA (docosahexaenoic acid) [20]. Chia seed oil is described by high substance of polyunsaturated fats in correlation with other vegetable oils. The healing idea of an eating regimen is affected not simply by the measure of omega- 3 ate up yet also by their degree to omega- 6 acids. The attractive extent is 4-5:1 between the supply of $\omega-6$ and $\omega-3$ acids [51]. In any case, this extent is a long way from prescribed (15-20:1) in the eating routine of a normal European occupant because of over the top utilization of $\omega-6$ unsaturated fats and immersed unsaturated fats. In chia seed oil the proportion of omega- 3 and omega- 6 is $0.33-0.35[12,48]$. The high substance of $\omega-3$ acids in chia seed oil empowers diminishment of the offer of $\omega-6$ acids in day by day sustenance proportions. Aside from that, a satisfactory supply of unsaturated fats diminishes the danger of ischemic coronary illness [34].

Proteins: Amino acids being distinctive frameworks are essential cell parts empowering typical capacity of the living being. The substance of proteins in chia seeds is $15-25 \%$, a large portion of them being prolamins (537 $\mathrm{g} / \mathrm{kg}$ of rough protein), trailed by glutelins $(231 \mathrm{~g} / \mathrm{kg}$ of unrefined protein), globulins $(71 \mathrm{~g} / \mathrm{kg}$ of rough protein) and albumins (40 $\mathrm{g} / \mathrm{kg}$ of unrefined protein) $[13,43]$. Patients experiencing celiac illness can devour chia seeds since they don't contain gluten proteins [40]. Chia seeds contain a larger number of proteins than rice, maize, grain or oats seeds $[33,36]$. It contains 18 amino acids, including 7 exogenous amino acids, which are thought to be essential. Olivos-Lugo et al., (2010) revealed that prevalent amino acid in chia seeds is glutamic acid which is in charge of legitimate working of the mind.

Dietary fiber: Fiber in chia seeds is $22-42 \%$, where the insoluble part makes around $85 \%$ and the solvent division makes around $15 \%$ [48]. The substance of fiber in chia seeds relies upon the area of development and atmosphere. The fiber content of chia is twice as compare with grain, four to five times more than almonds, soy, quinoa or amaranth. They may assume a vital part in prevention and treating infections of the stomach related and circulatory frameworks, diabetes, colorectal disease, hemorrhoids, kidney stones and metabolic issue [30].

Vitamins and minerals: For the proper functioning of the body vitamins and minerals also play an important role. A satisfactory supply of these components empowers ideal control of hormones secretions, growth with division of cells and tissues. It likewise shields the living being from oxidative stress. Chia seeds are a wellspring of B vitamins: Thiamin $(0.62 \mathrm{mg} / 100 \mathrm{~g})$, Riboflavin $(0.17 \mathrm{mg} / 100 \mathrm{~g})$, Niacin $(883 \mathrm{mg} / 100 \mathrm{~g})$ and folic acid (49 $\mathrm{mg} / 100 \mathrm{~g})$. The aggregate substance of vitamin $\mathrm{E}$ in chia seeds is $238-427 \mathrm{mg} / \mathrm{kg}$ and it is similar to shelled nut oil $(398.6 \mathrm{mg} /$ $\mathrm{kg})$, however it is lower than in linseeds $(588.5 \mathrm{mg} / \mathrm{kg})$, sunflower $(634.4 \mathrm{mg} / \mathrm{kg})$ or soybean $(1,797.6 \mathrm{mg} / \mathrm{kg})$. In examination with rice and maize seeds chia seeds contain more niacin and practically identical measures of thiamine and riboflavin [54]. Aside from that, chia seeds are a wellspring of minerals. As compare with dairy it contains 6 times more calcium, 11 times more phosphorus and 4 times more potassium. The iron substance of chia is likewise very high contrasted with most different seeds it has 6 times more iron as compare with spinach, 1.8 times more than lentils and 2.4 times more than liver [40].

\section{Food Applications}

The enthusiasm for considering chia as a conceivable nourishment added substance has emerged on account of its high substance of cancer prevention agents, proteins, fiber and furthermore its commitment of PUFA, which are gainful to wellbeing. The breads delivered with soy included with chia and flaxseed had extraordinary acknowledgment of the buyers uncovered by the sensorial assessment. Furthermore, they contained more elevated amounts of protein $(25 \%$ - 30\%) contrasted with business breads (21\%). Specifically, the additional breads of chia were rich in dietary fiber $(4 \%-5 \%)$ and the outcomes recommended that the breads displayed decreases in the take-up of glucose in the stomach related tract. Another possibly valuable wellbeing highlight was the high substance of PUFA, omega-9 (around 3\%), omega-6 (around 3\%), omega-3 (3\% - 4.5\%) and high calcium content (297 $\mathrm{mg} / 100 \mathrm{~g}$ ) exhibit in the breads [14]. Borneo et al., (2010) assessed how the substitution of eggs or oil in a cake plan with chia gel $(25 \%$, half and $75 \%)$ would influence the healthful substance fundamental practical properties and sensorial attributes of the item. In examination with control of oil and egg and watched that the substitution of eggs or oil in the cake definition by chia gel up to a level of $25 \%$ kept up the utilitarian and sensorial qualities of the item. Iglesias-Puig and Haros (2013) built up another pastry shop item by supplanting wheat flour with 5\% chia seeds and 5\% entire chia flour and presumed that chia seeds or their flour can be utilized as a fixing in the maker of prepared merchandise to build the healthful esteem and nature of the item, and the additional bread of chia seed was the most acknowledged by shoppers in contrast with the bread included of chia flour.

Utpott (2012) created included mayonnaise of chia, consolidated or not with other emulsifying added substances, with diminished oil substance and egg yolk, and kept up the practical attributes of the item, enhancing its sensorial and innovative perspectives. Rendon-Villalobos et al., (2012) created corn tortillas with 5\%, $10 \%, 15 \%$ and $20 \%$ of chia flour and all details displayed higher fiber, protein and lipid substance than corn tortillas being more noteworthy with $15 \%$ and $20 \%$ substitution. $(53 ; 14)$ developed a grain bar included with chia seed that exhibited sufficient physicosynthetic and microbiological properties, with high fiber content $(10.3 \%)$. Tangible adequacy $(84 \%)$ and aim to purchase $(96 \%)$ had acceptable outcomes. 
The considerable development of the basic unsaturated fats showcase is identified with the expansion of the utilization of dietary supplements that contain these mixes. Accordingly, consolidation into the eating routine of seeds, for example, chia, which contain high substance of these unsaturated fats, is especially alluring. In any case, a noteworthy test for the advancement of improved nourishment items is the acknowledgment criteria: item freshness, tangible qualities, appearance, stockpiling conditions, simplicity of arrangement and wellbeing be accomplished by Drusch and Mannino (2009) and dietary advantages. Pizarro et al., (2013) showed that the joining of chia flour and decreased substance of hydrogenated vegetable fat brought about a cake with higher nutritious esteem, for the most part in the omega- 3 unsaturated fat substance and the omega-6/omega- 3 proportion. What's more, it was conceivable to join chia flour into the cake details and to get an item with great innovative qualities (with little varieties in immovability and particular volume) and sensorial (with scores between 6, I loved it marginally, and 8, I loved it a ton). In connection to the aim to purchase, this was sure achieving $60 \%$ of the judges who conceivably or absolutely would purchase the cake. The nearness of hydrogenated vegetable fat limits the unfavorable impacts of chia flour on the particular volume and immovability of the cakes. Barrientos et al., (2012) utilizing Chia, a grain with astounding supplements were readied. The dietary esteem was dictated by estimating the synthetic piece, mineral substance and the unsaturated fat structure. Foods that are supplemented with chia flour contained essentialy high ratio of protein, $\omega-3$ acids, fat, calcium, zinc and insoluble fiber.

\section{Therapeutic Perspectives}

Attributable to the nearness of ALA at higher focuses and cell reinforcements numerous scientists have evaluated the defensive properties of chia seed and its oil against various infirmities.

Anti-hyperlipidemia and anti-hypercholestremia: Chia seeds contain a good amount of $\omega-3$, fiber and antioxidant which play a crucial role in lowering level of bad cholestrol. Chia has some unique characteristics that it has a soluble fiber covering outer its seed that when come in contact with water produce gum. This fiber slows down the process of conversion of carb into sugar that aid in maintaing insulin level. And also help in weight reduction and controling the diabetes that was main cause of high cholestrol. It promotes HDL and reduce LDL. Chia seeds have long chain triglycerides in appreciable amount to help in remove bad cholestrol from the aratery walls. Ayerza and Coates (2005) discovered in their study which was based on 24 male wistar rats that were devived into 3 groups in which one was fed with T1 corn oil, T2 with chia seed and T3 with chia oil for 4 weeks. When blood sample was taken there was decrease in LDL and serum triacylgycerol level and significant increase in HDL level in group T2 and T3. These results recommend that $\alpha$-linolenic loaded chia oil provide other sources of omega-3 to those inhabitants which are vegeterians and sensitive for fish and its products.

Anti-diabetic activity: Creus et al., (2016) discovered the possibly helpful physiological impacts of chia against the hazard factors for Type 2 diabetes in trial creatures. 6 month study done on rats by da Silva Marineli et al., (2015) in which $37 \mathrm{~g}$ of chia per day was given constantly which showed decrease in blood presssure, coagulation factor and inflammatory markers. demonstrated.
Good proportion in $\omega-3$ and $\omega-6$ help in reduction in inflammation and high amount of soluble fiber aid in managing the glucose level postprandialy.

Anti-cancer property: A food has an important part in the beginning and development of cancer. In different types of human cancer dieatry PUFAs participate a significant part in the reduction of cancer. The cytotoxic potential of PUFAs against various sorts of malignancy cells as well as might perform synergistically by present chemotherapeutic drugs. Apoptosis of cancer cells done through conversion of sphingomylein to ceramide due to ALA secretion of Arachidonic acid (20:4, n-6) which initiate it [21].

Anti-inflammatory property: Inflammation related issues are redness, pain, swelling and severity of which prompts loss of imperative capacities. The interdependent reaction chain is mediated by inflammation. Molecule released from white blood cells. Key inflammatory mediators include linoleic acid and its derivative eicosanoids, prostaglandin E2 and Leukotriene B4 is derived from arachidonic acid. However, chia proves low risk of proinflammatory reacti on seed oil diet. Chia seed oil contains n-3 PUFA is recommended competing with arachidonic acid membrane. Therefore, slightly modified prostaglandins and eicosanoids so induction of inflammation is induced by reducing cyclooxygenase- 2 (release prostaglandnin that speed up inflammation) [21].

Antioxidants activity: Chia contains an abundant number of antioxidants i.e. kamperfol, quercetin, chlorogenic acid, caffeic acid etc. These antioxidants scavange free radicals that cause cancer or onset aging. Many in vitro studies have done that proved its potent of antioxidant activity [47].

\section{Dietary recommendation}

Chia seed can be utilized as crucial edibles not surpass $48 \mathrm{~g}$ /day approved by the US Dietary Guidelines. Chia is commonly used in drinks, oats and as a dressing of salads as well as it can be cosumed raw. The Commission of Europe approved the consumption of breads substance with added chia seed should not exceed over $5 \%$. Chia seed or its oil rather than bread used for a range of edibles like bars, juices, breakfast grains, cake, snacks, organic product and yogurt. Although the fact that chia seeds are worthwhile as specified above, they may cause weight misfortune incited reactions such as enervation and weariness when ingested for a long stretch of time for example a few weeks. Further, around $10 \%$ of the general populations who take chia seeds experience the ill effects of loose bowels as specified previously [27].

\section{Material and Methods}

\section{Procurement of Raw Material}

The present research work was conducted in the nutrition lab at the University of Faisalabad. Chia seeds were obtained from AL Fatah Store, Faisalabad. All the chemicals and reagents were purchased from Sigma Aldrich.

\section{Preparation of Sample}

Chia seeds were grinded into flour by using electric grinder. After- 
wards, the flour was sieved through 60 mesh sized sieve in order to obtain uniform finely divided powder.

\section{Characterization of chia seed flour}

Chia seed flour was analyzed for

- Proximate composition

- Physico-chemical analysis

Proximate analysis: Chia seed flour was analyzed for moisture, crude protein, crude fiber, crude fat and ash by standard methods of AOAC (2005).

\section{i. Moisture content}

Moisture content was determined according to the AOAC method no. 945.15. For cereal adjuncts [2]. Approximately, sample $(10 \mathrm{~g})$ was weighed Sample was dried in $105 \pm 5^{\circ} \mathrm{C}$ hot air oven until constant weight. Sample was cooled in a desiccator before reweighing and moisture content was calculated.

Moisture content $(\%)=[($ wt of original sample $(\mathrm{g})-\mathrm{wt}$ of dried sample $(\mathrm{g})) /$ wt of original sample $(\mathrm{g})] \times 100$

\section{ii. Crude protein}

Crude protein was determined by using Kjeldahl's apparatus as described in AOAC method no. 945.18 [2]. Sample (2g) was weighed and taken in a digestion flask having $25 \mathrm{~g}$ digestion mixture $\left(\mathrm{FeSO}_{4}: \mathrm{ZnSO}_{4}: \mathrm{K}_{2} \mathrm{SO}_{4}\right)(1: 4: 95)$ and $25 \mathrm{~mL}$ of sulfuric acid and heat the solution on a heater. Heat the solution until it turns from brownish black color to greenish yellow color or transparent. The remaining solution was then diluted with $250 \mathrm{~mL}$ distilled water. Furthermore, take $10 \mathrm{~mL}$ to form $250 \mathrm{~mL} \mathrm{NaOH}$ (40\%). The ammonia thus liberated was condensed and collected in a flask containing of boric acid solution (4\%). Add 2 drops of methyl orange indicator in a flask containing ammonia and boric acid. Titration was done by adding standard $0.1 \mathrm{~N}$ sulfuric acid in a distillated solution until orange red end point.

Nitrogen $\%=$ [volume of $0.1 \mathrm{NH}_{2} \mathrm{SO}_{4} \times 0.0014 \times 250 /$ wt of sample $(\mathrm{g}) \times$ Volume of sample $(10 \mathrm{~mL})] \times 100$

Crude protein content $=\%$ Nitrogen $\times 5.7$

\section{iii. Crude fat}

Crude fat was determined by following the AOAC method no. 945.18 [2]. Sample (10g) via ethanol extraction using soxhlet fat extraction unit over a period of 2 hours. The fat content of chia flour was determined by the following formula;

Crude fat $(\%)=[(w t$ of extraction cup containing fat - wt of empty extraction cup)/wt of paper and sample - wt of filter paper] $\times 100$

\section{iv. Crude fiber}

Crude fiber was determined by following the method mentioned in AACC method no. 92-10 [1]. Firstly sample (2g) was added in a beaker containing $200 \mathrm{~mL}$ solution $1.25 \%$ of $\mathrm{H}_{2} \mathrm{SO}_{4}$ was poured in it. The beaker containing sample and solution was heated for 30 minutes. Residues obtained upon heating were filtered and washed for 2 to 3 times to make it acid free. The residues obtained were then transferred to another beaker containing $1.25 \% \mathrm{NaOH}$ of $200 \mathrm{~mL}$. The contents or resides heated again for 30 minutes. The residues again washed 2 to 3 times to make it alkali free. The residues obtained were transferred to a crucible and dried in an oven until smoking ceased out of the sample. The sample was then kept in muffle furnace for 3 hours at $550 \pm 5^{\circ} \mathrm{C}$. The sample was taken out when turns into grey ash and cooled in a desiccator and weighed. Difference was calculated by using the following formula:

Crude Fiber $(\%)=($ Loss in weight on ignition $/$ wt of sample $) \times$ 100

\section{v. Ash content}

Ash content was determined according to the AOAC method no. 927.02 (AOAC 2005). Sample (10g) was weighed exactly into predried and cooled china dish followed by heating on a burner until all the organic matter ignited. The ignited sample placed in a muffle furnace at $550 \pm 5^{\circ} \mathrm{C}$ temperature for about 3 hours. Ash was calculated by the following formula:

Ash $(\%)=[($ wt of original sample $(\mathrm{g})-\mathrm{wt}$ after heating sample $(\mathrm{g})) /$ wt of original sample] $\times 100$

\section{vi. Nitrogen free extract (NFE)}

Nitrogen free extract was calculated by the following:

Nitrogen free extract $(\mathrm{NFE})=100-(\%$ Moisture $+\%$ Crude Protein $+\%$ Crude Fat $+\%$ Crude Fiber $+\%$ Ash $)$

\section{Physicochemical analysis}

\section{i. Water holding and oil holding}

Water and oil holding capacity (WHC and OHC) were determined according to the methods described by Olivos-Lugo et al., (2010). Sample was added in $45 \mathrm{~mL}$ of water and then shaken in a water bath for about 1 hour and centrifuged at $2500 \times \mathrm{g}$ for $30 \mathrm{~min}-$ utes at $25^{\circ} \mathrm{C}$. The water layer was removed. The remaining sample and water held by sample within the centrifuged tube was exactly weighed. The results were exhibited as the mass $(\mathrm{g})$ of retained water per as the mass $(\mathrm{g})$ of sample.

Oil holding capacity was also calculated by using the same method as water holding capacity. The water used in WHC was substituted with canola oil in OHC method.

\section{ii. Water absorption index and water solubility index}

Water absorption index (WAI) and water solubility index (WSI) were measured as hydration properties by following the method of Choi et al., (2012) with minor modification. Chia seed flour $(3 \mathrm{~g})$ was dissolved in $30 \mathrm{~mL}$ distilled water and heated for 1 hour in a water bath at $60^{\circ} \mathrm{C}$. The supernatant was collected in pre- 
weighed dry aluminum dishes after centrifuging at $3000 \times \mathrm{g}$ for 15 minutes. The residues were void by allowing the sample tube to upend or stand inverted for 10 minutes. For measurements, the collected supernatant was dried in a hot air oven at $105^{\circ} \mathrm{C}$ overnight. The values were exhibited or displayed as the $\mathrm{g}$ water absorbed from chia seed flour and as the $\%$ water solubility index.

WAI $(\mathrm{g} / \mathrm{g})$ = wt of water uptake in hydrated residue / wt of chia seed flour

WSI $(\%)=[$ wt of dispersed solids in supernatant $/$ wt of chia seed flour $\times 100$

\section{Result and Discussion}

Chia seed is becoming enormously popular in modern food regimen in many countries due to its functional and nutritional properties. Apart from contributing to human nutrition chia helps in preventing various health related illnesses and increases satiety index and can be termed as "functional food". The selection of chia seed flour is due to high content of soluble fiber, omega-3, richness of antioxidants and good quality of protein content that give an alternative to healthy snack. The purpose of this study was to evaluate physico-chemical, and functional properties of chia seed flour. The results pertaining the various aspects of the study are given below.

\section{Chemical Analysis of chia seed flour}

Moisture: Water has a chief role in affecting both physical and chemical attributes of food products. Shelf-life of food commodities depends on its moisture content for example higher the flour moisture shorter will be the its storage stability (Mendonca et al., 2007). The moisture content of chia flour was $5.86 \pm 0.30 \%$ as given in table 4.1. Similarly, it was ranged from 4.5 to $7.8 \%$ Olivos-Lugo et al. (2010) and Coorey et al. (2012) in other commercially available varitieties of chia seed due to varied agro-climatic conditions of the specific growing area including soil type, temperature and rainfall.

Crude fat: Organic biochemical in lipids such as fats and oil are very important in our daily dietary requirements as they are structural component of cell memberane, major source of energy and help in production of vitamins and hormones. Lipids including fats and oil play a important role in contributing the overall physical attributes, control the quality and shelf life of food products. Fats and oils improve the texture, mouth feel and flavor of baked products and many prepared foods. The fat content of chia flour was $37.4 \pm 1.41$ as given in Table 4.1. Likewise, it was $37.77 \mathrm{~g} / 100 \mathrm{~g}$ reported by Olivos-Lugo et al., (2010) and Coorey et al., (2012). The content of fat in chia flour varies due to climatic conditions as in cool weather conditions increases the oil content.

Crude protein: Chia seed flour contain all the essential amino acids and helps in boosting cognitive function, lowering inflammation and supporting repair processes. The reason why chia seed flour is so beneficial because they have good amount of protein in it. The protein content of chia flour was $19.84 \pm 1.40$ as given in Table 4.1 which is in the range of 20 to $26 \mathrm{~g}$ Olivos-Lugo et al., (2010) and Coorey et al., (2012). The varying proportion of protein in chia based on the different growning location, weather conditions during the growning seasons and various types of nutrients amount in the soil.

Crude fiber: The estimation of amount lignin, cellulose and pectin that are indigestible and additional constituents of similar temperament present in food is known as crude fiber. Crude fiber contained less food value but provide bulkness to eatables which aid in specific physiological functions. Soluble fiber in baked products, breads etc are becoming very popular. Significant quantity of soluble fiber has an effect on different bread properties such as water holding capacity and solubility. The crude fiber content in chia flour was $37.82 \pm 1.19$ given in Table 4.1 which was in the range of 35-40 g/100g Olivos-Lugo et al., (2010) and Coorey et al., (2012). Due to different growing conditions the content of fiber varying. The content of fiber increased with the increasing level of chia.

Ash content: The ash content represents the concentration of mineral components in the given product which is left behind after the removal of moisture and organic components. Maturation stages of grain and climatic conditions have great impact on ash content.

The ash content of chia flour given in was $4.00 \pm 0.36$ given in Table 4.1 which is within the range of literature value $4.6-5.96 \%$ Olivos-Lugo et al., (2010) and Coorey et al., (2012). Ash content varies due to genetics of seed and non-genetic factors like climatic conditions, type of soil and use of fertilizers etc. The content of ash increased with the increasing level of chia.

Water holding capacity and oil holding capacity: The amount of water absorbed or the ability of a sample to hold or entrap the water molecules when external force or compression is applied is defined as the water holding capacity of that sample. Through the non-polar sites within the protein molecules the absorption of oil is defined as oil holding capacity. Higher effect of the water holding capacity of the sample may be due to the higher starch content which leads to the higher capacity of the sample to absorb water. Water holding capacity and oil holding capacity of chia seed flour was $12.06 \pm 0.32$ and $19.33 \pm 0.59$ given in Table 4.1. Likewise, it was 12.42 and 19.18 reported by Coorey et al., (2014) and Olivos-Lugo et al., (2010).

Water absorption index and water solubility index: The water absorption index is the ability or property of flour to absorb water and swell to desired consistency. Water solubility index is used to show the starch degradation or when the water is added to granules the number of free polysaccharides released determines the water solubility index. The factors affecting the varying results of the water solubilty index or the water absorption index depends on the nature of the raw material or the factors affecting the working of the equipment. Water absorption index (WAI) and water solubility index (WSI) of chia seed flour was $2.98 \pm$ 0.14 and $9.22 \pm 0.74$ given in Table 4.1. Similarly, which is in line with the findings of Choi et al., (2012) who reported water absorption index 2.83 and water solubility index 10.79. And comes in between the ranges as WAI ranges from 0.3 to 12.8 and WSI value ranges from 2.7 to $73.2 \%$ as described by Oikonomou and Krokida (2012). 
Table 1. Means of physico-chemical analysis of chia seed flour.

\begin{tabular}{|c|c|}
\hline Parameters & Means \\
\hline Moisture & $5.86 \pm 0.30$ \\
\hline Protein & $19.84 \pm 1.40$ \\
\hline Fiber & $37.82 \pm 1.19$ \\
\hline Fat & $37.40 \pm 1.41$ \\
\hline Ash & $4.00 \pm 0.36$ \\
\hline WHC & $12.06 \pm 0.32$ \\
\hline OHC & $19.33 \pm 0.59$ \\
\hline WAI & $2.98 \pm 0.14$ \\
\hline WSI & $9.22 \pm 0.74$ \\
\hline
\end{tabular}

WHC $=$ Water holding capacity; OHC $=$ Oil holding capacity WAI = Water absorption index; WSI = Water solubility inde

\section{Summary}

Chia also known as Salvia Hispanica, is an ancient plant belongs to a mint family. The Aztec and Mayas used chia seeds as their staple foodand to make therapeutic diets. In the central city of Mexico, chia itself labeled as an important crop. Chia seeds size ranges from $1 \mathrm{~mm}$ to $2 \mathrm{~mm}$ and are oval in shape. Chia has the ability to grow $1 \mathrm{~m}$ in length. Chia coloration ranges from dark brown to black. Now a day's chia plays an important role in pharmaceutical industries, makeup, food and animal feed due to its high nutritional profile. Food technologists and nutritionists start using this incredible seed as an alternative into the healthy products formulation in order to improve the functional and nutritional properties.

Chia seeds are rich in dietary fiber, protein, essential fatty acids and several other nutrients. Due to its high content of polyunsaturated fatty acids i.e. $37.40 \pm 1.41$, they help in lowering cholesterol, act as an anti-inflammatory, and improves or enhance cognitive ability. Chia seeds promote energy and endurance. They are also known as "Indian running foods" as athletes often consumed chia seed gel in order to boost or maintain energy and stamina.

Chia seeds often recommended to those who want to lose weight or maintain healthy weight as they are considered as natural appetite suppressant. Their ability to swell up and expand slows the digestion process and makes the person feel full for longer. They also help in maintaining healthy weight as chia seeds promote hydration due to its hydrophilic properties.

Chia seeds contain $37.82 \pm 1.19$ fiber. It is known for its constipation preventing property and beneficial in maintaining good healthy body weight and also helps in controlling diabetes and prevents cardiac diseases. It lowers the risk of colon diseases and possess great role in lowering cholesterol. Chia seeds contain $19.84 \pm 1.40$ protein which is an essential part of every cell in the body and helps to build and repair tissues. It is also important in the production of hormones and enzymes. Moisture content of chia seed flour was $5.86 \pm 0.30$ and ash content $4.00 \pm 0.36$.

Water holding capacity and oil holding capacity of chia seed flour was $12.06 \pm 0.32$ and $19.33 \pm 0.59$ and comprises of tremendous gelling or binding properties and can be used baked goods. Water absorption index of chia seed flour was $2.98 \pm 0.14$ and water solubility index was $9.22 \pm 0.74$.

Exceptionally, chia is gluten free so that it can be used by patients suffering from celiac disease. Antioxidants rich chia seeds stops the free radical damage to body cells by neutralizing them and shown their effect on reducing the risk of cardiovascular diseases and several carcinomas. The incorporation of $25 \mathrm{~g}$ of chia seeds in daily diet of post-menopausal women leads to increase in the plasma levels of alpha linolenic acid is 138\% and eicosapentaenoic acid is $30 \%$. By scrutinizing the good health aspects of chia seeds consumption on dyslipidemia and insulin reluctance generate by intake of sucrose rich diet showed that use of chia precludethe onset of dyslipidemia and insulin resistance.

\section{Conclusion}

Chia being rich in essential fatty acids, proteins, fiber, antioxidants and several minerals plays an important role in reducing various health related issues. Chia seeds comprises of amazing water holding capacity and moderate oil holding capacity. Hence, chia is a substantial contribution to the human dietary interventions.

\section{References}

[1]. AACC . Approved methods of the American association of cereal chemists. Methods. Inc. St. Paul, MN, USA. 2000;54:21.

[2]. William H. Official methods of analysis of AOAC International. 18th ed. Gaithersburg, Maryland, USA. 2000.

[3]. Aviara NA, Oluwole FA, Haque MA. Effect of moisture content on some physical properties of sheanut (Butyrospernum paradoxum). International Agrophysics. 2005;19(3):193.

[4]. Ayerza R. Effects of seed color and growing locations on fatty acid content and composition of two chia (Salvia hispanica L.) genotypes. Journal of the American Oil Chemists' Society. 2010 Oct; 87(10):1161-5.

[5]. Ayerza R, Coates W. Chia seeds: new source of omega-3 fatty acids, natural antioxidants, and dietetic fiber. Southwest Center for Natural Products Research \& Commercialization, Office of Arid Lands Studies, Tucson, Arizona, USA. 2001

[6]. Ayerza R, Coates W. Ground chia seed and chia oil effects on plasma lipids and fatty acids in the rat. Nutrition Research. 2005 Nov 1;25(11):995-1003.

[7]. Barrientos VA, Aguirre A, Borneo R. Chia (Salvia hispanica) can be used to manufacture sugar-snap cookies with an improved nutritional value. International Journal of Food Studies. 2012 Oct 15;1(2).

[8]. Borneo R, Aguirre A, León AE. Chia (Salvia hispanica L) gel can be used as egg or oil replacer in cake formulations. Journal of the American Dietetic Association. 2010 Jun 1;110(6):946-9.

[9]. Campos BE, Ruivo TD, da Silva Scapim MR, Madrona GS, Bergamasco $\mathrm{RD}$. Optimization of the mucilage extraction process from chia seeds and 
application in ice cream as a stabilizer and emulsifier. LWT-Food Science and Technology. 2016 Jan 1;65:874-83

[10]. Chica C. Conferencia Latinoamericana de cereals . ICC e International Association for Cereal Science. ICC. Santiago. 2011;39.

[11]. Choi I, han OK, chun J, kang CS, kim KH, kim YK, et al. Hydration and pasting properties of oat (Avena sativa) flour. Prev. Nutr. Food Sci. 2012 Mar;17(1):87-91. PMID: 24471068.

[12]. Ciftci ON, Przybylski R, Rudzińska M. Lipid components of flax, perilla, and chia seeds. European Journal of Lipid Science and Technology. 2012 Jul; 114(7): 794-800.

[13]. Coates W. Protein content, oil content and fatty acid profiles as potential criteria to determine the origin of commercially grown chia (Salvia hispanica L.). Industrial Crops and Products. 2011 Sep 1; 34(2):1366-71.

[14]. Coelho MS, de las Mercedes Salas-Mellado M. Revisão: Composição química, propriedades funcionais e aplicaçóes tecnológicas da semente de chia (Salvia hispanica L) em alimentos/Review: Chemical composition, functional properties and technological applications of chia (Salvia hispanica L) seeds in foods. Brazilian Journal of Food Technology. 2014 Oct 1;17(4):259.

[15]. Coorey R, Grant A, Jayasena V. Effect of chia flour incorporation on the nutritive quality and consumer acceptance of chips. Journal of Food Research. 2012;1:85-95

[16]. Creus A, MR Ferreira, ME Oliva, YB Lombardo. Mechanisms involved in the improvement of lipotoxicity and impaired lipid metabolism by dietary $\alpha$-linolenic acid rich Salvia hispanica 1 (salba) seed in the heart of dyslipemic insulin-resistant rats. J. Clin. Med. 2016 Jan 28;5(2). PMID: 26828527.

[17]. Da Silva Marineli R, CS Moura, EA Moraes, SA Lenquiste, PCB Lollo, PN Morato, et al. Chia (Salvia hispanica L.) enhances HSP, PGC-1 $\alpha$ expressions and improves glucose tolerance in diet-induced obese rats. Nutr. 2015 May; 31(5): 740-8. PMID: 25837222.

[18]. de Falco B, Amato M, Lanzotti V. Chia seeds products: an overview. Phytochemistry Reviews. 2017 Aug 1;16(4):745-60.

[19]. Drusch S, Mannino S. Patent-based review on industrial approaches for the microencapsulation of oils rich in polyunsaturated fatty acids. Trends in Food Science \& Technology. 2009 Jul 1;20(6-7):237-44.

[20]. Flachs P, M Rossmeisl, M Bryhn, J Kopecky. Cellular and molecular effects of $\mathrm{n}-3$ polyunsaturated fatty acids on adipose tissue biology and metabolism. Clin. Sci. 2009 Jan;116(1):1-16. PMID: 19037880.

[21]. Gazem RA, Chandrashekariah AS. Pharmacological properties of Salvia hispanica (chia) seeds: a review. Journal of Critical Reviews. 2016;3(3):63.

[22]. Gören AC, Kiliç T, Dirmenci T, Bilsel G. Chemotaxonomic evaluation of Turkish species of Salvia: Fatty acid compositions of seed oils. Biochemical Systematics and Ecology. 2006 Feb 1;34(2):160-4

[23]. Han JJ, Janz JA, Gerlat M. Development of gluten-free cracker snacks using pulse flours and fractions. Food Research International. 2010 Mar $1 ; 43(2): 627-33$.

[24]. Hernández LM. Mucílago de Chía (Salvia hispanica): microestructura, caracterización físico-química y aplicaciones en la industria alimentaria (Doctoral dissertation, Universidade de Santiago de Compostela). 2012; 1-120.

[25]. Iglesias-Puig E, Haros M. Evaluation of performance of dough and bread incorporating chia (Salvia hispanica L.). European Food Research and Technology. 2013 Dec 1;237(6):865-74.

[26]. Ixtaina VY, Martínez ML, Spotorno V, Mateo CM, Maestri DM, Diehl BW, Nolasco SM, Tomás MC. Characterization of chia seed oils obtained by pressing and solvent extraction. Journal of Food Composition and Analysis. 2011 Mar 1; 24(2): 166-74.

[27]. Kim Y, Kim H, inventors; Hanyang Patent Firm, assignee. Dietary supplement, feed and pharmaceutical composition containing chia seed and maca, and preparation method thereof. United States patent application US 13/390,064. 2012 Jun 7

[28]. Kislev ME, Simchoni O, Melamed Y, Maroz L. Flax seed production: evidence from the early Iron Age site of Tel Beth-Shean, Israel and from written sources. Vegetation History and Archaeobotany. 2011 Nov 1; 20(6):579584

[29]. Larsen R, KE Eilertsen, EO Elvevoll. Health benefits of marine foods and ingredients. Biotechnol. Advances. 2011 Sep-Oct; 29(5): 508-18. PMID: 21683131

[30]. Lasota B. Nutritional and functional properties of dietary fiber. Journal of NutriLife. 2014 Jul 13; 7

[31]. Lewis DC. The incorporation of chia (Salvia hispanica L.) seeds into baked products. University of Florida. 2010; $1-116$.

[32]. Lozano R, Naghavi M, Foreman K, Lim S, Shibuya K, Aboyans V, et al. Global and regional mortality from 235 causes of death for 20 age groups in 1990 and 2010: a systematic analysis for the Global Burden of Disease Study 2010. The lancet. 2012 Dec 15; 380(9859): 2095-128.

[33]. Marcinek K, Z Krejpcio. Chia seeds (Salvia hispanica L.): health promoting properties and therapeutic applications a review. roczniki panstwowego zakładu higieny. 2017;68(2):123-129. PMID: 28646829
[34]. Mcclements D, E Decker, J Weiss. Emulsion-based delivery systems for lipophilic bioactive components. J. food sci. 2007 Oct;72(8):R109-24. PMID: 17995616.

[35]. McManus A, M Merga, W Newton. Omega-3 fatty acids. What consumers need to know. Appetite. 2011 Aug; 57(1):80-3. PMID: 21497627.

[36]. Mendonça JC, Franca AS, Oliveira LS. A comparative evaluation of methodologies for water content determination in green coffee. LWT-Food Science and Technology. 2007 Sep 1;40(7):1300-3.

[37]. Minatelli JA, Hill WS, Moerck R, Nguyen U, inventors; US Nutraceuticals, assignee. Chia seed beverage and related method. United States patent application US 12/349,123. 2009 Jul 16.

[38]. Mohd Ali N, Yeap SK, Ho WY, Beh BK, Tan SW, Tan SG. The promising future of chia, Salvia hispanica L. BioMed Research International. 2012 Nov; 21.

[39]. Muñoz Hernández L. Mucilage from chia seeds (Salvia hispanica): microstructure, physico-chemical characterization and applications in food industry.

[40]. Muñoz LA, Cobos A, Diaz O, Aguilera JM. Chia seed (Salvia hispanica): an ancient grain and a new functional food. Food reviews international. 2013 Oct 2;29(4):394-408.

[41]. USDA National Nutrient Database for Standard Reference, Release 28 2018. Available online: http://www.ars.usda.gov/ba/bhnrc/ndl (accessed on 3 May 2019)

[42]. Oikonomou NA, Krokida MK. Water absorption index and water solubility index prediction for extruded food products. International journal of food properties. 2012 Jan 1;15(1):157-68

[43]. Olivos-Lugo B, Valdivia-Lopez M, Tecante A. Thermal and physicochemical properties and nutritional value of the protein fraction of Mexican chia seed (Salvia hispanica L.). Food Sci. Technol. Inter. 2010 Feb;16(1):89-96. PMID: 21339125.

[44]. Omobuwajo TO, Sanni LA, Olajide JO. Physical properties of ackee apple (Blighia sapida) seeds. Journal of Food Engineering. 2000 Jul 1;45(1):43-8.

[45]. Pizarro PL, Almeida EL, Sammán NC, Chang YK. Evaluation of whole chia (Salvia hispanica L.) flour and hydrogenated vegetable fat in pound cake. LWT-Food Science and Technology. 2013 Nov 1;54(1):73-9.

[46]. Rendón-Villalobos R, Ortíz-Sánchez A, Solorza-Feria J, Trujillo-Hernández CA. Formulation, physicochemical, nutritional and sensorial evaluation of corn tortillas supplemented with chia seed (Salvia hispanica L.). Czech Journal of Food Sciences. 2012 Mar 9;30(2):118-25.

[47]. Reyes-Caudillo E, Tecante A, Valdivia-López MA. Dietary fibre content and antioxidant activity of phenolic compounds present in Mexican chia (Salvia hispanica L.) seeds. Food Chemistry. 2008 Mar 15;107(2):656-63.

[48]. Sargi SC, Silva BC, Santos HM, Montanher PF, Boeing JS, Júnior S, et al Antioxidant capacity and chemical composition in seeds rich in omega-3: chia, flax, and perilla. Food Science and Technology. 2013 Sep;33(3):541-8.

[49]. Segura-Campos MR, Ciau-Solís N, Rosado-Rubio G, Chel-Guerrero L, Betancur-Ancona D. Chemical and functional properties of chia seed (Salvia hispanica L.) gum. International journal of food science. 2014.

[50]. Simopoulos AP, Cleland LG, editors. Omega-6/omega-3 essential fatty acid ratio: the scientific evidence. Karger Medical and Scientific Publishers; 2003.

[51]. Simopoulos AP. The importance of the omega-6/omega-3 fatty acid ratio in cardiovascular disease and other chronic diseases. Experimental biology and medicine. 2008 Jun;233(6):674-88

[52]. Timilsena YP, R Adhikari, S Kasapis, B Adhikari. Molecular and functiona characteristics of purified gum from Australian chia seeds. Carb. Poly . 2016 Jan 20;136:128-36.PMID: 26572338.

[53]. Tramujas JM, Carli CG, Prado NV, Lucchetta L, Tonial IB. Evaluación de la calidad nutricional y lipídica de barras de cereales saladas preparadas con diferentes aglutinantes. Revista chilena de nutrición. 2017;44(4):350-9.

[54]. Ullah R, M Nadeem, A Khalique, M Imran, S Mehmood, A Javid, et al. Nutritional and therapeutic perspectives of Chia (Salvia hispanica L.): a review. J. food sci. technol. 2016 Apr; 53(4):1750-8. PMID: 27413203.

[55]. Uribe JA, Perez JI, Kauil HC, Rubio GR, Alcocer CG. Extraction of oil from chia seeds with supercritical CO2. The Journal of Supercritical Fluids. 2011 Mar 1;56(2):174-8.

[56]. US Department of Agriculture. 2004. Seeds, chia seeds, dried. Nutrient Database for Standard Reference, Release 27: Basic Report: 12006. Report Date, March 16, 2015

[57]. Utpott M. Use of chia (Salvia hispanica L.) mucilage to replace mayonnaise fat and / or egg yolk. 2012. 50 f. Monograph (Bachelor of Food Engineering) - Federal University of Rio Grande do Sul, Porto Alegre. 2012.

[58]. Valdivia-López MÁ, Tecante A. Chia (Salvia hispanica): a review of native Mexican seed and its nutritional and functional properties. InAdvances in food and nutrition research. Academic Press. 2015 Jan ; 75: 53-75.

[59]. Valdivia-López MÁ, Tecante A. Chia (Salvia hispanica): a review of native Mexican seed and its nutritional and functional properties. Adv Food Nutr Res. 2015 Jan 1; 75: 53-75. PMID: 26319904. 